\title{
Can be sleep disturbances as prodromal of $\mathrm{MCl}$ ?
}

Keywords: dementia, AD, MCI, clinical features, sleep

\section{Opinion}

The world's elderly population grows at an unprecedented rate; although inevitable and has contrary effects on socioeconomic of community, the health of older people and finally quality of life. This worldwide phenomenon unavoidably result in increasing number of age-related disorders specially neurodegenerative disorders such as Alzheimer's disease (AD) and Mild Cognitive Impairment (MCI). ${ }^{1}$

Mild cognitive impairment has been considered as middle stage from normal aging to dementia. About $12 \%$ persons with this condition develop Alzheimer's disease annually, and $80 \%$ at 6 years follow-up. ${ }^{2,3}$

Although, MCI has not been known as an obvious dementia, could be the preclinical or very early stage of AD. Since diagnosis criteria for MCI are still debatable, early detection of MCI is invaluable. ${ }^{4}$ However, Petersen et al. ${ }^{5}$ in 2004 has defined the essential features of these criteria for MCI include, memory complaint reported mostly by an informant, objective memory impairment for age, essentially preserved general cognitive function, and of course, largely intact functional activities. ${ }^{5}$ Totally, MCI is classified into two categories. The above mentioned criteria usually define the amnestic MCI subtype (a-MCI), but, the second one is when no memory impairment is present (na-MCI).

For more experts that work in the field, combination of evaluations can account for a passable diagnosis of MCI. These evaluations include clinical features, neuropsychological testing, biomarkers and neuroimaging. The neuropsychiatric symptoms as a branch of clinical features, have been extensively studied and the most common are apathy (11.7-68\%), depression (20-56\%), anxiety (14.1-54\%), and sleeping problems (18.3-56\%). ${ }^{6-9}$ Since sleep plays a crucial role in learning and memory across the lifespan, and thus is it not surprising that its disturbances and even deprivation is also associated with the decline in cognitive functioning and in degenerative diseases increasing amyloid- $\beta .^{10,11}$ Recently, some studies have indicated alterations of phasic events of NREM sleep in MCI/AD patients as integrated signs of cognitive problems. ${ }^{12-14}$ Sleeping problems are common in dementia in which they result in a deterioration of memory because the consolidation of memories is made during the sleep time. Consequently, the alterations in the person's brain with $\mathrm{AD}$ or MCI can led to alterations in sleep architecture. ${ }^{15}$

By and large, it is recommended beside of common cognitive evaluations for MCI detection, the evaluation of sleep, as non-cognitive feature in those with possible risk for dementia may be relevant and maybe necessary and because a lot of studies have demonstrated that sleep disorders treatment improves cognitive performances, it could be considered as a target for early intervention.
Volume I Issue 5 - 2017

\author{
Ahmad R Khatoonabadi \\ Department of speech therapy, Tehran University of Medical \\ Sciences, Iran
}

Correspondence: Ahmad R Khatoonabadi, Department of speech therapy, Tehran University of Medical Sciences, Iran, Email Khatoonabadi@tums.ac.ir

Received: October 30, 2017 | Published: December 21, 2017

\section{Acknowledgements}

None.

\section{Conflicts of interest}

The author declared that there are no conflicts of interest.

\section{References}

1. Asia's Aging Population. East-West Center Research Program, Population and Health Studies. Honolulu; 2002.

2. Morris JC, Storandt M, Miller JP, et al. Mild cognitive impairment represents early-stage Alzheimer disease. Arch Neurol. 2000;58(3):397405 .

3. Larrieu S, Letenneur L, Orgogozo JM, et al. Incidence and outcome of mild cognitive impairment in a population based prospective cohort. Neurology. 2002;59(10):1594-1599.

4. Chong MS, Sahadevan S. Preclinical Alzheimer's disease: diagnosis and prediction of progression. Lancet Neurol. 2005;4(9):576-579.

5. Petersen RC. Mild cognitive impairment as a diagnostic entity. J Intern Med. 2004;256(3):183-194.

6. Geda YE, Roberts RO, Knopman DS, et al. Prevalence of neuropsychiatric symptoms in mild cognitive impairment and normal cognitive aging: population-based study. Arch Gen Psychiatry. 2008;65(10):1193-1198.

7. Lyketsos CG, Lopez O, Jones B, et al. Prevalence of neuropsychiatric symptoms in dementia and mild cognitive impairment: results from the cardiovascular health study FREE. JAMA. 2002;288(12):1475-1483.

8. Ramakers IH, Visser PJ, Aalten P, et al. Affective symptoms as predictors of Alzheimer's disease in subjects with mild cognitive impairment: a 10year follow- up study. Psychol Med. 2010;40(7):1193-1201.

9. Muangpaisan W, Intalapaporn S, Assantahcai P. Neuropsychiatric symptoms in the community-based patients with mild cognitive impairment and the influence of demographic factors. Int $J$ Geriatr Psychiatry. 2008;23(7):699-703.

10. Poe GR, Walsh CM, Bjorness TE. Cognitive neuroscience of sleep. Prog Brain Res. 2010;185:1-19. 
11. Ju YS, Ooms SJ, Sutphen C, et al. Slow wave Sleep disruption increases cerebrospinal fluid amyloid- $\beta$ levels. Brain. 2017;140(8):2104-2111.

12. De Gennaro L, Gorgoni M, Reda F, et al. The fall of sleep k-complex in Alzheimer disease. Sci Rep. 2017;3(7):39688.

13. Gorgoni M, Lauri G, Truglia I, et al. Parietal fast sleep spindle density decrease in Alzheimer's disease and amnesic mild cognitive impairment. Neural Plast. 2016;2016:8376108.
14. Mander BA, Marks SM, Vogel JW, et al. $\beta$-amyloid disrupts human NREM slow waves and related hippocampus-dependent memory consolidation. Nat Neurosci. 2015;18(7):1051-1057.

15. Palmer K, Berger AK, Monastero R, et al. Predictors of progression from mild cognitive impairment to Alzheimer disease. Neurology. 2007;68(19):1596-1602. 